\title{
Acute Response of Toe-Spread-Out Exercise on Medial Longitudinal Arch Height and Balance
}

\author{
Jinseon Kim', Jusung Lee', Daeyoung Kim², Boymirzozoda Islomjon', Bobokyaw², Kichung \\ Lee $^{3}$, Tejin Yoon ${ }^{1,4, *}$ \\ ${ }^{1}$ Interdisciplinary Program in Biohealth-machinery Convergence Engineering, Kangwon National University, Korea \\ ${ }^{2}$ Department of Sport Science, Kangwon National University, Korea \\ ${ }^{3}$ Department of Physical Education, Chuncheon National University of Education, Korea \\ ${ }^{4}$ Department of Physical Education, Kangwon National University, Korea
}

Received: December 19, 2020

Accepted: January 12, 2021

Published online: January 31, 2021

Keywords:

Dynamic Balance

Intrinsic Foot Muscle Exercise

Medial Longitudinal Arch

Static Balance

Toe-Spread-Out Exercise
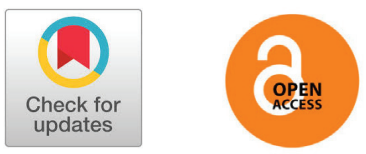

\section{ABSTRACT}

OBJECTIVES This study was to determine the acute response of the toe-spread-out exercise(TSE) on the medial longitudinal arch height(MLAH) and the static and dynamic balance.

METHODS Twenty-four healthy young males and females were randomly assigned to the exercise group $(n=12)$ or to the control group $(n=12)$. The exercise group performed 40 repetitions of TSE while the control group had a rest on the chair. Before and after the exercise or rest, MLAH was measured while standing. One-leg standing test was conducted on the force plate with eyes closed and open. The total distance of the center of pressure (COP) was calculated to assess the static balance. Y-balance test was performed; and the anterior, and medial/lateral posterior reach distances were measured to assess the dynamic balance.

RESULTS There was an interaction between group and time for the MLAH $(p<.001)$, and the MLAH in the exercise group increased after the exercise $(2.03 \pm 1.01 \mathrm{~mm} ; \mathrm{t}=-6.930, \mathrm{p}<.001)$. There was an interaction between group and time for the anterior reach distance during the $Y$-balance test $(p=.023)$, and the distance in the exercise group showed a strong tendency to increase after the exercise $(t=-2.104, p=.059)$. No interaction was found for the total distance of the COP.

CONCLUSIONS The 40 repetitions of TSE increased MLAH and showed a positive effect on dynamic balance in healthy young males and females. These results suggest that TSE can be useful as a new exercise method to improve the foot arch structure and function. Further research with the longer duration of TSE training for various populations is warranted.

( T) The Asian Society of Kinesiology and the Korean Academy of Kinesiology
서론

발은 걷는 동안 충격을 흡수하기 위해 유연성이 요구 되며, 동시에 추진력을 위해 비교적 견고해야 한다. 따 라서 발에는 충격흡수, 유연성 그리고 내구성 등의 요 구들을 충족시키기 위해 적절한 상호작용을 하는 관절,

*Correspondence: Tejin Yoon, Interdisciplinary Program in Biohealth-machinery Convergence Engineering, Physical Education, Kangwon National University, 1, Kangwondaehak-gil, Chuncheon, Gangwon-do; Tel: +82-033-250-6787; Fax: +82033-259-5680; E-mail: tyoon@kangwon.ac.kr
결합조직 그리고 근육 등의 구조물이 있다[1]. 이와 같 은 발의 구조물들에 의해 발의 아치가 형성되며, 발의 아치는 내측 종 아치, 외측 종 아치 그리고 횡 아치 총 세 개의 아치가 있다. 그 중 내측 종 아치는 일차적으로 발에 가해지는 부하를 지지하는 구조로 충격을 흡수하 고 분산시키는 중요한 역할을 한다[2,3].

발이 정상적인 기능을 하기 위해서는 아치가 지면으 로부터 일정한 높이를 유지해야 하지만, 선천적 변형, 
발 근육의 약화, 반복적 사용에 의한 근피로 등은 내측 종 아치의 높이를 낮아지게 한다[4]. 내측 종 아치의 높 이가 낮아지게 되면 지면으로부터 오는 충격을 흡수하 지 못하고 무릎관절, 엉덩관절, 허리뼈와 같은 몸쪽 부 위로 직접 부하가 전달된다[5]. 또한 발의 과도한 회내 (excessive pronation)와 같은 비정상적 정렬을 초래 할 수 있으며 [1], 균형능력을 저하시키고[6], 결과적으 로 족저근막염과 무지외반증 등과 같은 손상들을 초래 할 수 있다[7-9]. 따라서 발의 온전한 사용을 위해 내측 종 아치의 형태와 기능을 유지하는 것은 매우 중요하다.

내측 종 아치의 형태는 일차적으로 제 1 중족골, 내 측 설상골, 주상골, 종골 그리고 거골 등의 뼈로 이루어 져 있다[10]. 이차적으로 내측 종 아치의 형태와 기능 은 족저근막, 인대, 외재근, 내재근 등에 의해서 유지된 다[4]. 특히, 발의 외재근과 내재근은 내측 종 아치를 지지하는데 중요한 역할을 하는 것으로 알려져 있으며 [11], 발의 내재근과 외재근의 근력은 아치의 높이와 직접적인 관련이 있다고 보고되었다 $[8,12,13]$. 따라서, 아치의 높이를 적절히 유지하고 발의 기능을 정상적으 로 유지하기 위해서는 발의 외재근과 내재근을 강화하 는 운동이 필요하다.

발의 외재근과 내재근을 강화할 수 있는 운동에는 발가락 말기 운동(toe curl exercise)과 짧은 발 운동 (short foot exercise), 발가락 벌리기 운동(toe spread out exercise)이 있다 $[7,14]$. 다수의 선행연구들이 발 가락 말기 운동과 짧은 발 운동이 주상골 하강을 감 소시키고 균형능력을 향상시키는 것으로 보고하였다 $[6,8,12,13,15,16]$. 특히, 무지외전근은 내측 종 아치 의 안정화에 중요한 역할을 하는데[17], 발가락 벌리기 운동 시 다른 운동방법들보다 무지외전근의 근활성도가 높게 나타났으며 $[18,19]$, 무지외전근의 단면적이 증가 된 것으로 나타났다[20]. 이와 같이 선행연구의 결과를 볼 때, 발가락 벌리기 운동이 내측 종 아치의 형태와 기 능을 유지하기 위한 운동방법으로 효과적일 것으로 판단 된다. 하지만, 높은 가능성에도 불구하고 발가락 벌리기 운동의 중장기적인 효과는 물론 즉각적인 효과를 검증 한 연구조차 이루어져 있지 않다. 따라서 본 연구의 목 적은 건강한 성인남녀를 대상으로 일회성 발가락 벌리 기 운동이 내측 종 아치의 높이와 정적 및 동적 균형능 력에 미치는 영향을 규명하는 것이다. 선행연구를 기반 으로 본 연구의 가설은 다음과 같이 설정하였다. 첫째,
발가락 벌리기 운동 후 내측 종 아치의 높이는 증가할 것이다. 둘째, 정적 및 동적 균형능력은 향상될 것이다.

\section{연구방법}

\section{연구대상}

이 연구의 참여자는 이전에 짧은 발 운동, 발가락 말 기 운동, 발가락 말기 운동 등과 같은 아치의 개선을 위 한 발 운동을 경험해본 적이 없는 만 18세 37세 24명 의 성인남녀를 학내게시판을 통해 모집하였으며, 당뇨 병 환자와 최근 6 개월간 하지에 신경 외과적 수술을 받 은 자, 전정계 장애, 어지러움 그리고 낙상 경험 등 균형 능력에 영향을 미칠 수 있는 병력이 있는 자는 제외하 였다. 모든 참여자는 참여하기 전 실험과정에 대한 충 분한 설명을 들었으며, $\mathrm{K}$ 대학교 연구윤리위원회의 승 인(KWNUIRB-2020-07-001-001)을 받은 연구참여 동의서에 자발적으로 동의하였다. 각각의 참여자는 운 동군과 통제군 중 한 집단으로 임의 배정하였다. 연구참 여자의 신체적 특성은 <Table 1 >에 제시된 바와 같다.

\begin{tabular}{lcc}
\multicolumn{3}{l}{ Table 1. Participant characteristics. } \\
\hline Variable & EG $^{\text {a }}(\mathbf{n}=12)$ & CG $^{\text {a }}(\mathbf{n}=\mathbf{1 2})$ \\
\hline Age (years) & $21.2 \pm 2.3$ & $23.9 \pm 6.6$ \\
Height (cm) & $170.8 \pm 6.9$ & $169.5 \pm 7.4$ \\
Weight $(\mathrm{kg})$ & $69.4 \pm 12.4$ & $70.8 \pm 11.5$ \\
BMla $\left(\mathrm{kg} / \mathrm{cm}^{2}\right)$ & $23.6 \pm 3.0$ & $24.5 \pm 2.5$ \\
Leg length (cm) & $95.5 \pm 5.1$ & $94.6 \pm 5.4$ \\
Foot length (mm) & $252.3 \pm 12.3$ & $245.6 \pm 12.8$ \\
\hline a EG, exercise group; CG, control group; BMl, body mass index
\end{tabular}

\section{측정항목 및 통계분석}

\section{1) 내측 종 아치의 높이}

이 연구의 모든 참여자들은 우성발을 사용하여 진 행하였으며, 우성발은 공을 차는 발로 기준하여 선정하 였다. 내측 종 아치 높이는 주상골 하강검사(Navicular drop test)를 사용하여 비 체중부하와 체중부하 자세에 서 측정하였으며, 모든 참여자는 동일한 검사자에 의해 측정되었다. 비 체중부하 시 내측 종 아치의 높이에 대 한 급내상관계수는 단일측도 $\operatorname{ICC}(2,1)=0.955, \mathrm{P}<.001$ 로 나타났으며, 평균측도 $\operatorname{ICC}(2,1)=0.984, \mathrm{P}<.001$ 로 나타났다. 체중부하 시 내측 종 아치의 높이에 대한 급 
내상관계수는 단일측도 $\operatorname{ICC}(2,1)=0.986, \mathrm{P}<.001$ 로 나 타났으며, 평균측도 $\operatorname{ICC}(2,1)=0.995, \mathrm{P}<.001$ 로 나타났 다. 참여자는 양발을 어깨너비로 벌려 의자에 편안하게 앉아있는 상태에서 발을 딱딱한 표면에 평평하게 놓은 뒤 무릎관절을 $90^{\circ}$ 굴곡하여 거골하관절을 중립위치에 놓았다. 비 체중부하 시 내측 종 아치의 높이는 참여자 가 의자에 앉아있는 상태에서 주상골 조면의 가장 두드 러진 지점을 촉진하여 펜으로 표시한 뒤 지면으로부터 표시지점까지의 수직 거리를 측정하였다. 참여자는 검 사자의 지시에 따라 발 위치의 변화 없이 정면을 응시 한 채 가능한 한 양발에 체중이 고르게 분산되도록 일 어선 상태에서 체중부하 시 내측 종 아치의 높이를 측 정하였다. 각 자세에서 내측 종 아치의 높이는 3 회씩 측 정하였다[21].

\section{2) 정적 균형능력}

정적 균형능력을 측정하기 위해 힘측정판(OR6-72000, AMTI, USA)위에서 눈 뜨고 감은 조건에 대해 한 발 서기 검사를 실시하였다[22]. 실험이 준비된 참여자 는 검사자의 지시에 따라 힘측정판 위에 올라가 비 우 성 다리의 엉덩관절과 무릎관절을 각각 $90^{\circ}$ 굴곡하고, 양손을 교차하여 가슴 앞에 고정시킨 상태에서 우성다 리로 서서 균형을 유지하도록 하였다. 눈 뜬 조건은 참 여자가 $3 \mathrm{~m}$ 앞 벽의 표시지점을 응시한 채로 균형을 유 지하였으며, 눈 감은 조건은 눈 뜬 조건에서 눈만 감은 채로 균형을 유지하였다. 각 조건을 임의의 순서로 10 초간 2 번씩 측정하였으며, 힘측정판의 3 축 방향의 힘과 모멘트 값을 $1000 \mathrm{~Hz}$ 로 샘플링하였다.

\section{3) 동적 균형능력}

동적 균형능력은 $\mathrm{Y}$-균형검사(Y-balance test)를 사 용하여 측정하였다. 실험 전 검사자의 시범에 따라 참여 자는 각 방향에 대해 2회씩 연습을 진행하였다. 준비된 참여자는 검사자의 지시에 따라 앞쪽 방향을 바라보고 선 후 양손은 허리 위에 고정한 상태로 앞쪽, 뒤안쪽 그 리고 뒤가쪽 방향으로 뻗을 수 있는 최대한 다리를 뻗 도록 유도하였다. 비 우성발이 땅에 닿거나, 시작 자세 로 돌아오지 못하는 경우 재측정하였다. 지지하고 있는 우성발의 중심점에서 뻗은 다리인 비 우성발의 발끝까 지의 거리를 측정하였으며, 순서는 임의로 진행하여 각 방향에 대해 2회씩 측정하였다[3,6].

\section{4) 발가락 벌리기 운동}

발가락 벌리기 운동을 진행하기 전에 운동방법에 대 한 자세한 설명과 영상을 통해 교육을 진행하였다. 운 동군에 해당하는 참여자들은 의자에 편하게 앉아 발목 관절을 $30^{\circ}$ 배측굴곡한 상태에서 모든 발가락을 신장 시킨 후, 제 5 지골을 가쪽방향으로 지면에 내려놓으며 제 1 지골을 안쪽방향으로 지면에 내려놓은 자세를 3 초 간 유지하였다[23]<Figure 1>. 발가락 벌리기 운동을 40회 반복하여 수행하였으며, 충분한 무지외전근의 근 활성도를 유도하기 위하여 반복횟수를 설정하였다. 검 사자는 참여자가 동작을 정확하게 수행하는지 육안으로 확인하였다. 근전도를 무지외전근에 부착하여 운동 시 근육의 활성도를 확인하여 피드백하였다.

\section{A}

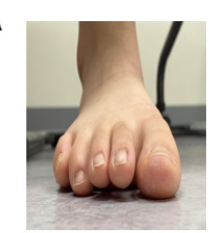

(a)

B

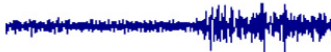

Figure 1. Toe-spread-out exercise. A, (a) first-relax (b) second-lifting the toe (c) third-flexing little toe toward lateral side (d) fourth-flexing great toe toward medial side; B, EMG data when toe-spread-out exercise

\section{자료처리}

내측 종 아치의 높이는 각각 비 체중부하와 체중부 하 시 3 회 측정한 주상골의 수직 높이의 평균을 구하고 체중으로 나누어 표준화하였다. 정적 균형능력은 한 발 서기 시 힘측정판으로 수집한 10 초의 데이터에서 변동 성을 최소화하기 위해 측정 초기 2 초와 마지막 2 초를 제외하여 사용하였다. 각각 눈 뜬 조건과 눈 감은 조건 에 대해 압력중심의 총 이동거리를 산출하였으며 [24], 발 길이로 표준화하였다. 동적 균형능력은 $\mathrm{Y}$-균형검사 를 사용하여 앞쪽, 뒤안쪽 그리고 뒤가쪽 방향으로 다 리뻗기 거리를 다리길이로 표준화하였다. 모든 자료처 리는 엑셀 프로그램(Microsoft Excel)을 이용하였다.

\section{통계처리}

산출된 모든 변인에 대해 Shapiro-Wilk 검사를 실시 하여 정규 분포를 따르는 것을 확인하였다. 발가락 벌리 기 운동이 내측 종 아치의 높이, 압력중심의 이동거리 및 
이동속도 그리고 다리뻗기 거리에 미치는 영향을 검증하 기 위해 혼합설계 이원분산분석(mixed model design two-way ANOVA)을 실시하였다. 분석 결과 집단과 시 기 간 교호작용이 나타났을 때, 각각 운동 전과 후 시점 에서 종속변인에 대한 대응표본 $\mathrm{T}$-검정을 실시하려 최 종적으로 운동의 효과를 통계적으로 판단하였다. 또한, 운동의 효과크기를 검증하기 위해 Cohen's d를 실시하 였다. 통계적 유의수준은 $a=0.05$ 로 설정하였으며, 모든 통계처리는 SPSS Version 24.0을 사용하였다.

\section{결과}

\section{내측 종 아치의 높이}

발가락 벌리기 운동에 따른 각 집단의 내측 종 아치 의 높이는 <Table 2 >와 같다. 비 체중부하 시 내측 종 아치의 높이에서 집단과 시기 간 교호작용이 나타나지 않았다 $(\mathrm{p}=0.279)$. 체중부하 시 내측 종 아치의 높이에 서는 집단과 시기 간 교호작용이 나타났다 $(\mathrm{p}<.001)$. 운 동군의 경우 사후 측정에서 체중부하 시 내측 종 아치 높이가 유의하게 증가하였으나 $(\mathrm{t}=-6.930, \mathrm{p}<.001)$, 통 제군의 경우 유의한 차이가 나타나지 않았다 $(\mathrm{t}=-1.496$, $\mathrm{p}=.163)$. 체중부하 시 발가락 벌리기 운동의 효과 크기 는 작게 나타났다 $(\mathrm{d}=0.2)$.

\begin{tabular}{|c|c|c|c|c|c|}
\hline \multirow{2}{*}{ Variable } & \multirow{2}{*}{ Group } & \multicolumn{2}{|c|}{ Time } & \multirow{2}{*}{ Effect } & \multirow{2}{*}{ F-value } \\
\hline & & Baseline & Post & & \\
\hline \multirow{3}{*}{$\begin{array}{l}\text { Sitting } \\
\text { MLAH } \\
\left(\mathrm{mm} \cdot \mathrm{BW}^{-1}\right)\end{array}$} & $E G(n=12)$ & $0.70 \pm 0.13$ & $0.71 \pm 0.13$ & G & 0.29 \\
\hline & & & & $\mathrm{T}$ & .665 \\
\hline & $C G(n=12)$ & $0.70 \pm 0.10$ & $0.70 \pm 0.10$ & $\mathrm{G} \times \mathrm{T}$ & 1.233 \\
\hline \multirow{3}{*}{$\begin{array}{l}\text { Standing } \\
\text { MLAH } \\
\left(\mathrm{mm} \cdot \mathrm{BW}^{-1}\right)\end{array}$} & $E G(n=12)$ & $0.57 \pm 0.14$ & $0.60 \pm 0.14^{\#}$ & G & 0.39 \\
\hline & $C G(n=12)$ & $0.57+0.08$ & $0.58+0.08$ & $\mathrm{~T}$ & $40.026^{t+}$ \\
\hline & $C G(n=12)$ & $0.57 \pm 0.08$ & $0.58 \pm 0.08$ & $\mathrm{G} \times \mathrm{T}$ & $19.749^{* *}$ \\
\hline
\end{tabular}

Values are displayed as mean $\pm \mathrm{SD} ; \mathrm{MLAH}$, medial longitudinal arch height; $\mathrm{EG}$, exercise group; $\mathrm{CG}$, control group; BW, body weight; $\mathrm{G}$, group; T, time

"Significant difference from baseline

'Significant difference between time ${ }^{\dagger} p<.05 ;{ }^{+\dagger} p<.001$

"Significant goupxtime interaction " $p<.05$; " $p<.001$

\section{정적 균형능력}

발가락 벌리기 운동에 따른 각 집단의 정적 균형능력 관련 변인의 결과는 <Table $3>$ 과 같다. 한 발 서기 시 눈 뜨고, 눈 감은 조건 모두에 대해 집단과 시기 간 교호 작용이 나타나지 않았다 $(\mathrm{p}=0.893, \mathrm{p}=0.277)$.
Table 3. Distance COP during the single-leg standing with eyes open and eyes closed.

\begin{tabular}{|c|c|c|c|c|c|}
\hline \multirow{2}{*}{ Variable } & \multirow{2}{*}{ Group } & \multicolumn{2}{|c|}{ Time } & \multirow{2}{*}{ Effect } & \multirow{2}{*}{ F-value } \\
\hline & & Baseline & Post & & \\
\hline \multirow{2}{*}{$\begin{array}{l}\text { Distance of } \\
\text { COP with } \\
\text { SEO } \\
\left(\mathrm{cm} \cdot \mathrm{FL}^{-1}\right)\end{array}$} & $E G(n=12)$ & $1.45 \pm 0.35$ & $1.50 \pm 0.36$ & G & 0.43 \\
\hline & $C G(n=12)$ & $1.48 \pm 0.32$ & $1.51 \pm 0.21$ & $\begin{array}{c}T \\
G \times T\end{array}$ & $\begin{array}{l}.732 \\
.019\end{array}$ \\
\hline \multirow{2}{*}{$\begin{array}{l}\text { Distance of } \\
\text { COP with } \\
\text { SEC } \\
\left(\mathrm{cm} \cdot \mathrm{FL}^{-1}\right)\end{array}$} & $E G(n=12)$ & $3.16 \pm 1.03$ & $2.78 \pm 0.75^{\#}$ & G & .314 \\
\hline & $C G(n=12)$ & $3.54 \pm 1.28$ & $2.79 \pm 0.66^{\#}$ & $\begin{array}{c}T \\
G \times T\end{array}$ & $\begin{array}{c}11.631^{+} \\
1.241\end{array}$ \\
\hline \multicolumn{6}{|c|}{$\begin{array}{l}\text { Values are displayed as mean } \pm \mathrm{SD} ; \mathrm{COP} \text {, center od pressure; } \mathrm{SEO} \text {, } \\
\text { single-leg standing with eyes open; } \mathrm{SEC} \text {, signle-leg standing with eyes } \\
\text { closed; } \mathrm{FL} \text {, foot length; } \mathrm{EG} \text {, exercise group; } \mathrm{CG} \text {, control group; } \mathrm{G} \text {, group; } \\
\mathrm{T} \text {, time } \\
\text { "Significant difference from baseline } \\
\text { 'Significant difference between time }{ }^{\dagger} \mathrm{p}<.05\end{array}$} \\
\hline
\end{tabular}

\section{동적 균형능력}

발가락 벌리기 운동에 따른 각 집단의 동적 균형능력 관련 변인의 결과는 <Table 4>와 같다. Y-균형 검사 시 앞쪽방향으로의 다리뻗기 거리에서 집단과 시기 간 교 호작용이 나타났다 $(\mathrm{p}=.023)$. 운동군의 경우 사후측정 에서 앞쪽방향으로의 다리뻗기 거리가 증가하는 경향 이 나타났다 $(\mathrm{t}=-2.104, \mathrm{p}=.059)$. 앞쪽방향으로 발가락 벌리기 운동의 효과 크기는 중간으로 나타났다 $(\mathrm{d}=0.4)$. 뒤안쪽방향과 뒤가쪽방향에서 집단과 시기 간 교호작용 이 나타나지 않았다 $(\mathrm{p}=.052, \mathrm{p}=.437)$.

Table 4. Reach distance during Y-balance test with anterior and posterior-medial, posterior-lateral direction.

\begin{tabular}{|c|c|c|c|c|c|}
\hline \multirow{2}{*}{ Variable } & \multirow{2}{*}{ Group } & \multicolumn{2}{|c|}{ Time } & \multirow{2}{*}{ Effect } & \multirow{2}{*}{ F-value } \\
\hline & & Baseline & Post & & \\
\hline \multirow{2}{*}{ 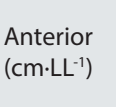 } & $E G(n=12)$ & $0.77 \pm 0.07$ & $0.80 \pm 0.07^{\#}$ & G & .091 \\
\hline & $C G(n=12)$ & $0.78 \pm 0.05$ & $0.77 \pm 0.05$ & GXT & $6.005^{*}$ \\
\hline \multirow{2}{*}{$\begin{array}{l}\text { Posterior- } \\
\text { Medial } \\
\left(\mathrm{cm} \cdot \mathrm{LL}^{-1}\right)\end{array}$} & $E G(n=12)$ & $0.89 \pm 0.10$ & $0.95 \pm 0.10^{\#}$ & $\begin{array}{l}G \\
T\end{array}$ & $\begin{array}{c}.331 \\
30.010^{+}\end{array}$ \\
\hline & $C G(n=12)$ & $0.88 \pm 0.11$ & $0.91 \pm 0.09^{\#}$ & $\mathrm{G} \times \mathrm{T}$ & 4.227 \\
\hline \multirow{2}{*}{$\begin{array}{l}\text { Posterior- } \\
\text { Lateral } \\
\left(\mathrm{cm} \cdot \mathrm{LL}^{-1}\right)\end{array}$} & $E G(n=12)$ & $0.92 \pm 0.07$ & $0.95 \pm 0.08^{\#}$ & G & .309 \\
\hline & $C G(n=12)$ & $0.91 \pm 0.10$ & $0.93 \pm 0.06$ & $\begin{array}{c}T \\
G \times T\end{array}$ & $\begin{array}{c}7.561^{\dagger} \\
.626\end{array}$ \\
\hline
\end{tabular}

Values are displayed as mean $\pm S D$; LL, leg length; $E G$, exercise group; $\mathrm{CG}$, control group; $\mathrm{G}$, group; $\mathrm{T}$, time

"Significant difference from baseline

'Significant difference between time ${ }^{\dagger} p<.05$

"Significant goup $x$ time interaction " $\mathrm{p}<.05$ 


\section{논의}

이 연구는 건강한 성인을 대상으로 발가락 벌리기 운 동이 내측 종 아치의 높이와 정적 및 동적 균형능력에 미 치는 영향을 분석하고자 하는데 그 목적이 있다. 이 연구 를 통해 나타난 주요결과는 다음과 같다. 첫 번째, 발가 락 벌리기 운동 후 체중부하 시 내측 종 아치의 높이가 증가하였다. 두 번째, 발가락 벌리기 운동 후 한 발 서기 검사 시 눈 감은 조건에서 압력중심의 총 이동거리에는 변화가 없었다. 세 번째, 발가락 벌리기 운동 후 $\mathrm{Y}$-균형 검사 시 앞쪽 방향으로의 다리뻗기 거리가 증가하였다.

본 연구에서 발가락 벌리기 운동 후 체중부하 시 측 정한 내측 종 아치의 높이는 평균적으로 $2.0 \mathrm{~mm}$ 정도 증가하였다. 이러한 결과는 발가락 말기의 효과(1.8-3.9 $\mathrm{mm}$ ) 또는 짧은 발 운동의 효과 $(2.2-5.5 \mathrm{~mm})$ 를 보고한 선행논문들의 결과와 비교할 만하다 $[8,15]$. 본 연구의 결과에 나타난 효과 크기는 작은 정도(Cohen's d= 0.2) 에 그치고 있고, 증가의 정도도 선행연구와 비교할 때 상대적으로 낮은 것으로 보인다. 하지만, 선행연구들 이 짧게는 4 주 길게는 8 주까지 발 운동을 실시하여 얻 은 결과이며, 본 연구에서 실시한 발가락 벌리기 운동 이 약 5 분 정도 소요된 것을 고려하면 주목할 만한 긍정 적인 결과이다. 물론 개개인의 반응 정도가 다르며, 증 가된 종 아치의 높이가 지속될 수 있는지는 확인 할 수 없었지만, 운동 집단의 모든 참여자가 증가하는 결과를 보인 점 $<$ Figure $2>$ 은 향후 발 아치의 구조를 유지하고 향상시키기 위한 새로운 발 운동으로서 발가락 벌리기 운동의 가능성을 충분히 보여주는 것이라 사료된다. 본 연구로는 발가락 벌리기 운동 후 내측 종 아치의 높이 가 증가된 이유를 직접적으로 밝힐 수는 없다. 하지만, 무지외전근의 근활성도가 클수록 발 운동으로 인한 내 측 종아치의 높이 증가가 크게 나타났다는 선행연구결 과를 근거로 그 이유를 찾을 수 있을 것이다[15]. 즉, 발 가락 벌리기 운동으로 엄지 발가락을 최대한 벌려 추가 적으로 무지외전근의 근활성이 더 크게 나타나고 스트 레치 되어 긴장된 상태가 유지되기 때문이라는 것이다 [18]. 같은 맥락에서 다른 선행연구는 발의 트러스 구 조에 수직력이 가해지면 발바닥 근막과 근육이 스트레 칭 되며, 발의 수축성 기계의 특성을 변화시켜 근육이 더 큰 힘을 생성한다고 설명하였다[25]. 끝으로, 본 연 구에서는 발가락 벌리기 운동 시 무지외전근에 근전도
전극을 부착하여 근전도 신호를 운동 시 피드백을 제공 하였다. 이를 통해 참여자가 최대한 정확한 동작으로 목 표하는 근육을 자극하도록 노력한 점도 내측 종 아치의 높이가 증가하게 된 결과의 부분적인 이유라 사료된다.

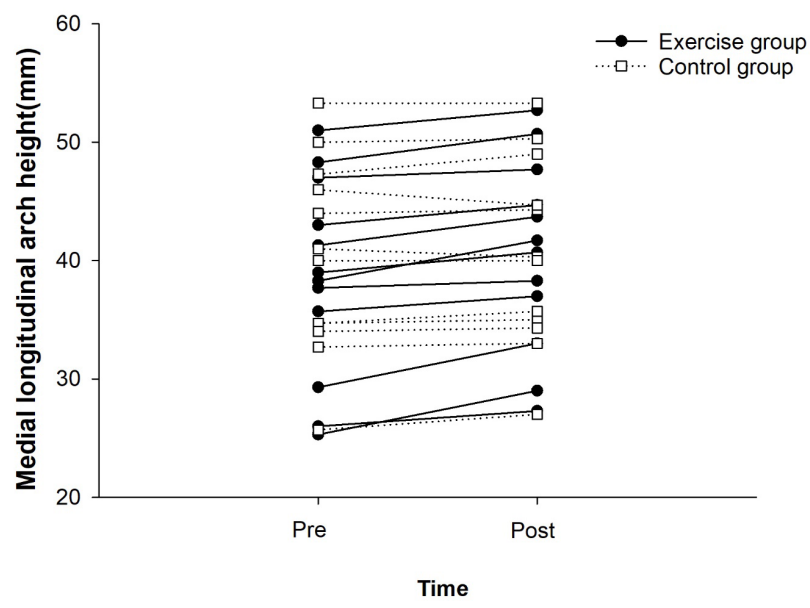

Figure 2. Comparison of medial longitudinal arch height in exercise group and control group

본 연구에서 발가락 벌리기 운동 후 한 발 서기 검사 시 눈 뜨고, 눈 감은 조건에서 압력중심의 총 이동거리 는 집단 간에 유의한 차이가 나타나지 않았다. 본연구 의 결과는 4 주간 짧은 발 운동 후 운동군과 통제군 모 두 압력중심의 좌우 움직임이 감소하여 두 그룹 간 유 의한 차이를 확인하지 못한 선행연구의 결과와 유사하 다[3]. 하지만, 본 연구 결과와는 다르게 짧은 발 운동 을 최소 4 주에서 최대 8 주 동안 수행한 선행연구는 정 적 균형능력이 유의하게 증가했다고 보고하였다[8,26]. 또한 5 주간 짧은 발 운동 후 정상발 집단과 비교하여 평 발 집단에서만 유의한 증가를 확인한 연구에 의하면 정 상발 집단의 경우 천장효과로 인해 효과가 없었을 것이 라고 설명하였다[27]. 본 연구에서 정상발을 가진 집단 을 대상으로 하여 발가락 벌리기 운동을 일회성으로 수 행하였기 때문에 운동의 효과가 나타나기 쉽지 않은 것 으로 판단된다.

본 연구의 동적 균형능력의 결과는 운동군의 경우 앞 쪽 방향으로만 그룹과 시기 간의 교호작용이 나타났다. 다만, 운동군의 경우 통제군과 비교하여 약하지만 모든 방향으로 운동의 효과가 나타났다. 이러한 결과는 발가 락 벌리기 운동이 다른 운동방법들에 비해 무지외전근의 근활성도가 높게 나타나기 때문이라고 판단된다[19]. 
그러한 이유는 선행연구에서 짧은 발 운동이 발가락 말 기 운동과 비교하여 무지외전근의 근활성도가 높게 나 타나며[7], 구심성경로를 자극하여 정보를 받아들이는 데 효과적이라고 설명하였기 때문이다[15]. 즉, 무지외 전근의 활성화로인해 고유수용성감각이 자극되고 구심 성 자극이 증가하여 동적 균형능력이 향상되었다고 설 명할 수 있다[28]. 본 연구에서 $\mathrm{Y}$-균형검사 시 뒤안쪽 방향과 뒤가쪽방향으로 유의한 차이가 나타나지 않은 이유는 학습효과로 인해 사후에 두 집단 모두 각 방향 으로 다리뻔기 거리가 증가하였고 그 효과의 크기가 운 동에 의한 영향보다 큰 것으로 판단된다. 이와 유사한 선행연구에서는 높은 동적 균형능력을 유지하기 위해 서는 발, 슬관절, 고관절 그리고 몸통과 팔에 이르는 보 다 총체적인 관절 움직임의 협응성과 체성감각이 요구 된다고 설명하였다[29]. 본 연구의 결과에 앞쪽방향으 로 나타난 운동의 효과 크기는 중간 정도(Cohen's d= 0.4)이지만, 일회성 운동이라는 점에서 운동의 효과를 판단하기에 충분하다고 생각한다.

본 연구는 두 가지 제한점을 갖는다. 첫 번째, 건강한 성인남녀를 대상으로 진행하였기 때문에 모든 대상에게 적용하기에는 제한이 있다. 두 번째, 본 연구에서는 우 성발만을 사용하여 운동을 진행한 점이다. 따라서, 추후 연구에는 선행연구를 참고하여 양발을 사용하여 다양한 발목각도에서 운동의 효과를 규명할 필요가 있다[7,12]

\section{결론}

본 연구결과 5 분간 40 회 반복하는 일회성 발가락 벌 리기 운동이 건강한 성인남녀를 대상으로 내측 종 아치 의 높이를 증가시키며, 동적 균형능력에 긍정적인 영향 을 미치는 것으로 나타났다. 따라서 본 연구에 사용된 발 가락 벌리기 운동은 향후 때와 장소를 가리지 않고 누구 나 스스로 수행할 수 있는 효율적인 발 건강 운동 방법 으로 발전할 수 있을 것으로 기대한다. 균형능력이 저하 되는 노인, 무지외반증과 평발 등과 같은 발 질환자, 발 부상으로 재활이 요구되는 운동선수 등을 대상으로 장 -단기적인 운동의 효과를 검증하는 후속연구가 필요할 것으로 판단된다.

\section{Acknowledgments}

이 논문은 2019년도 교육부의 재원으로 한국연 구재단의 지원을 받아 수행된 기초연구사업임(No. 2019S1A5A2A01047705). 또한 본 연구는 2019년도 강원대학교 대학회계 학술연구 조성비(520190085), 2020년 대학혁신지원사업 도전 연구비 지원 프로그램 의 지원을 받아 수행되었다.

\section{References}

1. Neumann DA. Kinesiology of the musculoskeletal systeme-book: foundations for rehabilitation. Elsevier Health Sciences. 2013.

2. Fiolkowski P, Brunt D, Bishop M, Woo R, Horodyski M. Intrinsic pedal musculature support of the medial longitudinal arch: an electromyography study. J Foot Ankle Surg. 2003; 42(6):327-333.

3. Lynn SK, Padilla RA, Tsang KK. Differences in static-and dynamic-balance task performance after 4 weeks of intrinsic-foot-muscle training: the short-foot exercise versus the towel-curl exercise. J Sport Rehabil. 2012; 21(4):327-333.

4. Saeki J, Tojima M, Torii S. Relationship between navicular drop and measuring position of maximal plantar flexion torque of the first and second-fifth metatarsophalangeal joints. J Phys Ther Sci. 2015; 27(6):1795-1797.

5. Franco AH. Pes cavus and pes planus: analyses and treatment. Phys Ther. 1987; 67(5):688-694.

6. Kim EK, Kim JS. The effects of short foot exercises and arch support insoles on improvement in the medial longitudinal arch and dynamic balance of flexible flatfoot patients. J Phys Ther Sci. 2016; 28(11):31363139.

7. Jung DY, Kim MH, Koh EK, Kwon OY, Cynn HS, Lee WH. A comparison in the muscle activity of the abductor hallucis and the medial longitudinal arch angle during toe curl and short foot exercises. Phys Ther Sport. 2011; 12(1):30-35.

8. Mulligan EP, Cook PG. Effect of plantar intrinsic muscle training on medial longitudinal arch morphology and 
dynamic function. Man Ther. 2013; 18(5):425-430.

9. Hwang R, Choi YJ. A Study on the Effects of Short Foot Exercise on Medial Longitudinal Arch and balance on the Foot and Efficient Application: Literature Review. Exercise Science. 2018; 27(4):252-259.

10. Birinci T, Demirbas SB. Relationship between the mobility of medial longitudinal arch and postural control. Acta Orthop Traumatol Turc. 2017; 51(3):233-237.

11. Mignogna CA, Welsch LA, Hoch MC. The effects of shortfoot exercises on postural control: a critically appraised topic. Int J Athl Ther Train. 2016; 21(6):8-12.

12. Hashimoto T, Sakuraba K. Strength training for the intrinsic flexor muscles of the foot: effects on muscle strength, the foot arch, and dynamic parameters before and after the training. J Phys Ther Sci. 2014; 26(3):373376.

13. Tsuyuguchi R, Kurose S, Seto T, et al. The effects of toe grip training on physical performance and cognitive function of nursing home residents. J Physiol Anthropol. 2019; 38(1):11.

14. Tourillon R, Gojanovic B, Fourchet F. How to evaluate and improve foot strength in athletes: an update. Front Sports Act Living. 2019; 1:46.

15. Chung KA, Lee E, Lee S. The effect of intrinsic foot muscle training on medial longitudinal arch and ankle stability in patients with chronic ankle sprain accompanied by foot pronation. Phys Ther Rehabil Sci. 2016; 5(2):78-83.

16. Matsumoto S, Fujita D, Osaka H. Intrinsic Foot Muscle Training Affects Plantar Pressure Distribution during A Single-group Clinical Trial. Kawasaki journal of medical welfare. 2019; 24(2):71-76.

17. Wong YS. Influence of the abductor hallucis muscle on the medial arch of the foot: a kinematic and anatomical cadaver study. Foot Ankle Int. 2007; 28(5):617-620.

18. Goo YM, Heo HJ, An DH. EMG activity of the abductor hallucis muscle during foot arch exercises using different weight bearing postures. J Phys Ther Sci. 2014; 26(10):1635-1636.

19. Kim MH, Kwon OY, Kim SH, Jung DY. Comparison of muscle activities of abductor hallucis and adductor hallucis between the short foot and toe-spread-out exercises in subjects with mild hallux valgus. J Back Musculoskelet Rehabil. 2013; 26(2):163-168.

20. Kim MH, Yi CH, Weon JH, Cynn HS, Jung DY, Kwon OY. Effect of toe-spread-out exercise on hallux valgus angle and cross-sectional area of abductor hallucis muscle in subjects with hallux valgus. J Phys Ther Sci. 2015; 27(4):1019-1022.

21. Charlesworth, S. J., \& Johansen, S. M. Navicular Drop Test. User Guide and Manual. Amsterdam: Hogeschool van Amsterdam. 2010; 1-8.

22. Shin YH, Youm CH, Son MJ. Effects of Foot Type and Ankle Joint Fatigue Levels on the Trajectories of COP and COM during a Single-Leg Stance. Korean J Sport Biomech. 2013; 23(4):335-345.

23. Gooding TM, Feger MA, Hart JM, Hertel J. Intrinsic foot muscle activation during specific exercises: a T2 time magnetic resonance imaging study. J Athl Train. 2016; 51(8):644-650.

24. Prieto TE, Myklebust JB, Hoffmann RG, Lovett EG, Myklebust BM. Measures of postural steadiness: differences between healthy young and elderly adults. IEEE Trans Biomed Eng. 1996; 43(9):956-966.

25. Yamauchi J, Koyama K. Force-generating capacity of the toe flexor muscles and dynamic function of the foot arch in upright standing. J Anat. 2019; 234(4):515-522.

26. Lee HS, Kim EJ, Park IS, et al. The Effects of Combined Exercise of Elastic-Band and Short Foot Exercise on Plantar Foot Pressure, Toe Angle and Balance for Patients with Low to Moderate Hallux Valgus. J Korean Soc Integ Med. 2015; 3(3):73-88.

27. Kim JS, Lee MY. The effect of short foot exercise using visual feedback on the balance and accuracy of knee joint movement in subjects with flexible flatfoot. Medicine. 2020; 99(13):e19260.

28. Moon DC, Kim K, Lee SK. Immediate effect of short-foot exercise on dynamic balance of subjects with excessively pronated feet. J Phys Ther Sci. 2014; 26(1):117-119.

29. Won KH, Lee MG. Effects of a strength exercise training for foot intrinsic muscle on height of medial longitudinal arch and balance in females aged 20's. Exercise Science. 2010; 19(4):351-360. 